HISPANICA 45 (2001)

\title{
"Los santos inocentes": naturaleza y progreso insolidario
}

\section{Ceferino PUEBLA PEDROSA}

\section{INTRODUCCIÓN}

Los santos inocentes, novela de Miguel Delibes publicada en 1981, es una de las obras literarias más representativas de los años 80 en España. Delibes, que habia escrito buenas novelas del realismo social, a partir de 1966 (cuando publicó Cinco horas con Mario) intensificó su actitud crítica ante las injusticias sociales y su defensa de los valores humanos. Además esa novela, junto con Parábola del náufrago (1969) y Los santos inocentes, tienen muchas innovaciones técnicas, al estilo de la novela "experimental" de aquella época: monólogo interior, saltos temporales, estilo indirecto libre, diversos narradores, etc. Los santos inocentes presenta otra novedad tipográfica original. Cada capítulo está escrito sin puntos, como si fuese una sola frase, es decir, sólo con comas y cambio de línea en los párrafos diferentes. Los diálogos están insertados sin rayas indicadoras ni comillas en línea aparte dentro del texto.

Esta novela narra la vida dentro de un cortijo latifundista de Extremadura en los años 60, las relaciones de opresión-sumisión entre los señores y los criados, la pasión por la caza del dueño del cortijo y las actividades de los familiares del "inocente" Azarías, que ahorca al amo para vengarse porque éste había matado un pájaro criado por él. Novela experimental en la forma y muy crítica en el contenido, es una de las obras maestras de Delibes. Tiene bastante reducción espacio-temporal, personajes bien caracterizados, lenguaje coloquial y estilo "oral" que hacen de ella una obra muy original.

En este artículo voy a estudiar el tema de la naturaleza muy apreciada por unos y expoliada por otros de los personajes de esta novela; y, como consecuencia, analizaré también las injusticias de un progreso insolidario y antiecológico que todavia perdura y puede ser muy peligroso para el hombre y su entorno natural. 


\section{UNIDAD TEMÁTICA Y AUTONOMÍA PARCIAL}

\subsection{Estructura, personajes y léxico}

Los santos inocentes tiene una estructura característica. Se compone de 6 capitulos, que el autor llama Libros, y cada uno de ellos tiene su título y cierta autonomía, como si se tratase de relatos casi independientes. Esto se nota sobre todo en los 3 primeros libros (titulados "Azarías", "Paco, el Bajo" y "La milana"), escritos hacia 1963. Estos 3 libros son la primera parte de la novela, y en ellos se presenta a los personajes, especialmente a Azarías y su pasión por los pájaros (la "milana"). También vemos cómo era el cortijo, la pobreza y falta de instrucción de los criados, la prepotencia de los amos y las relaciones entre los miembros de la familia de Régula y Paco, el Bajo, cuñado de Azarías. Los libros cuarto, quinto y sexto fueron redactados mucho después, hacia 1980, como dice el mismo Delibes: "La milana y el segundo libro y parte del tercero se escribieron seguidos. (La primera se publicó en el tiempo en que fue escrita, en 1963). Ahí se interpuso otro libro y éste no lo acabé hasta muchos años después, meses antes de publicarlo en 1981" (1).

Por ello, el libro cuarto (titulado "El secretario") forma la segunda parte de la novela y ahí se cuentan las aptitudes extraordinarias de Paco, el Bajo, como secretario, o ayudante de caza, y su sumisión total al señorito Iván. También se narra el episodio de las firmas ininteligibles de los criados como demostración de su pretendida culturización. Finalmente las visitas de la Marquesa al cortijo muestran el paternalismo en el trato de los criados por parte de los terratenientes. La tercera parte de la novela comprende los libros quinto y sexto (titulados "El accidente" y "El crimen"). Aquí vemos los dos accidentes de Paco cuando se rompe el peroné al caerse en la cacería, el trabajo de Azarias como ayudante de caza del señorito Iván, la muerte de la milana disparada por éste, y la venganza de Azarías que ahoga con una soga al señorito. Este episodio cierra bruscamente la novela.

A pesar de la multiplicidad de sucesos, esta novela tiene una cohesión temática muy fuerte, marcada por el enfrentamiento entre la ideología y arrogancia de los señoritos opresores y las actitudes serviles y a veces algo rebeldes de los humillados sirvientes. Junto con este tema principal, el espacio y el tiempo dan unidad a la narración. El espacio donde se desarrolla la acción 
es bastante reducido: dos cortijos de una región española próxima a la "raya", o frontera con Portugal. Probablemente se trate de una zona de Extremadura cercana al país vecino. A diferencia de otras novelas de Delibes ( $E l$ camino<1950>, Las ratas<1962>, El disputado voto del señor Cayo<1978>, etc.) cuya acción se desarrolla en pequeños pueblos de Castilla, en Los santos inocentes el escenario es un cortijo en pleno campo extremeño, donde abundan los latifundios. Delibes describe minuciosamente el monte que rodea al cortijo, con su flora y fauna características. También presenta la zona de viviendas donde viven los señores y los criados, señalando la enorme diferencia de comodidades entre ambas construcciones. Además en esta novela, como en otros relatos de Delibes, las actividades de caza son narradas con detalle, lo que evidencia el amplio conocimiento y experiencia que el autor tiene de ese tema. En esta obra el espacio vital tiene mucha importancia y ejerce gran influencia en las actitudes de los personajes. Los criados nunca salen del cortijo; por eso, su vida está limitada en todos los aspectos por las injustas condiciones del ambiente donde habitan. En ese sentido el cortijo manifiesta la estructura jerárquica del latifundio y revela las diferencias sociales de la gente que vive allí. Así, como dice Domingo Gutiérrez en su excelente análisis de Los santos inocentes, "el paisaje del cortijo tiene valor por sí mismo: transmite una fuerte impresión de realidad y se constituye en fuente de conocimiento de un modo de vida peculiar. Es factor imprescindible para dotar a los episodios de cohesión. Es un gran escenario por el que discurren los personajes y el elemento que traba el aparente desorden de los episodios" (2).

El tiempo histórico de esta narración no está indicado claramente, pero por algunos indicios vemos que se trata de finales de los años $60^{(3)}$. Era una época todavía muy dura para la gente del campo, a donde no habían llegado aún el progreso económico y la industrialización iniciados ya en las ciudades españolas. No había todavía apertura ni participación de los ciudadanos en la política, controlada por el franquismo mediante la falacia de la mal llamada "democracia orgánica" y un único partido político. Referente al tiempo narrativo de esta novela, en los libros primero al cuarto el tiempo es largo, repetitivo, y no se narran los acontecimientos en sucesión temporal lineal. Por eso, el autor usa libremente el tiempo y hay desorden cronológico, analepsis 
(flash-back), simultaneidad narrativa, etc. Así el ritmo de los 4 primeros libros es lento e inconexo. En los libros quinto y sexto el tiempo narrativo es muy breve ( 3 semanas aproximadamente). Abarca los 20 últimos días de un mes de octubre, cuando se hace la caza de las palomas migratorias. Aquí la narración de los episodios es lineal y seguida, en orden cronológico, y el ritmo es muy rápido. Con ello se logra una gran tensión dramática que conduce a la tragedia final. Todos los elementos empleados dan a esta obra un realismo y verosimilitud muy especiales ${ }^{(4)}$.

El léxico de esta novela es sumamente coloquial, con numerosos vocablos y expresiones propios del lenguaje hablado de los campesinos. La narración y el diálogo son las formas de expresión más usadas en esta obra. A veces hay descripciones rápidas que nos muestran las condiciones del ambiente y la psicología de los personajes. Se usan mucho los pronombres personales para iniciar el diálogo, vocativos vulgares, imperativos, interjecciones, exageraciones, modismos populares, expresiones obscenas, dativos éticos, la partícula polivalente "que", el artículo delante de nombres propios, etc. Es un lenguaje rural, de base "oral" y estilo lírico que se resume en la frase "milana bonita", repetida innumerables veces por Azarias. Veamos un ejemplo: "y el Azarías se agachó, tomó a la Niña Chica en sus brazos, se sentó al borde del talud, junto a la tierra removida, la oprimió contra sí y musitó, milana bonita” (5).

\subsection{Pasiones encontradas e injusticias}

Además de las coordenadas espacio-temporales que cohesionan la narración, hay en Los santos inocentes una unidad argumental que deriva de su tema central: la injusticia social de una situación vergonzosa, aceptada por los criados con sumisión y considerada como algo normal por los señores. La injusticia no sólo se manifiesta en las desigualdades que separan a los dos grupos (casa, vestidos, ocupaciones, etc.). Se muestra, sobre todo, en la prepotencia y desprecio con que algunos poderosos (Iván, don Pedro, el señorito de La Jara, etc.) tratan a sus servidores. También se hace patente esa injusticia en los abusos que cometen los amos: Nieves, hija de Paco, tiene que trabajar en casa de don Pedro, sin poder ir a la escuela; Azarías es expulsado a sus 61 años del primer cortijo por hacer lo mismo de siempre; Paco es obligado 
a salir de caza con una pierna escayolada, lo que produce la rotura del hueso por segunda vez. Estos abusos no tienen solución a corto plazo, porque los amos poseen una ideología inmovilista y egoista. Una muestra de esa ideología son estas palabras del señorito Iván, enfadado porque Quirce no le hacía caso ni quiso recibir una propina por la caza: "hoy a los jóvenes les molesta aceptar una jerarquía, pero es lo que yo digo, el que más y el que menos todos tenemos que acatar una jerarquía, unos debajo y otros arriba, es ley de vida, ¿no?” (6).

Sorprende en esta novela la actitud de sumisión total por parte de los siervos: Paco, Régula, Nieves, Rogelio, los demás criados y criadas, etc. Sólo Quirce, el hijo mayor de Paco, se enfrenta con su silencio y falta de adulación al señorito Iván. Pero es Azarías quien se rebela de modo más brutal asesinándolo. Esta rebelión trágica es casi inevitable, pero no tiene un sentido social, como veremos. Delibes en esta novela presenta el enfrentamiento de dos concepciones del mundo: la de los dueños, que abusan de la naturaleza y de los hombres; y la de los criados, fundada en una relación normal con el medio ambiente y sus compañeros. Delibes ha sido acusado de cierto "maniqueísmo" en la caracterización de sus personajes novelescos. En Los santos inocentes también vemos algún vestigio de esa ideología: casi todos los poderosos tienen rasgos negativos de maldad, injusticia, egoísmo y crueldad; los humildes aparecen en general con cualidades positivas: bondad, generosidad, cariño. Pero en esta novela parece que Delibes ha intentado corregir algo ese maniqueísmo: don Pedro es opresor y oprimido, la señorita Miriam y René el francés tienen buenas maneras y conciencia social. En definitiva, vemos en esta novela una confrontación de pasiones fuertes: la pasión por la caza del señorito Iván y la pasión por la milana de Azarías. Cuando estas dos aficiones irracionales chocan frontalmente, se produce la tragedia final. Pero esas pasiones se han enfrentado por causa de una situación de injusticia y opresión de los poderosos sobre gente humilde, que no tenía medios de superar esas circunstancias adversas.

Delibes en Los santos inocentes vuelve a plantear el problema serio del odio y la violencia como males inherentes a las relaciones sociales de los españoles. Aparece ese tema en Las ratas (1962), Parábola del náufrago (1969), 377A, madera de héroe (1987) y, sobre todo, en Las guerras de nuestros 
antepasados (1975) y El disputado voto del señor Cayo (1978). En estas novelas la violencia e intolerancia son una plaga extendida en toda la sociedad franquista. En Los santos inocentes ese odio y agresión no se afirman de todo el pueblo español, sino solamente de una clase opresora bien caracterizada. Como dice Pedro Carrero, "en Los santos inocentes Delibes ha abandonado esa concepción del odio y de la violencia como patrimonio común, casi podríamos decir como patrimonio nacional. La crueldad y la violencia no han desaparecido, pero figuran ahora polarizadas en un estamento social muy concreto: el que representa el dueño del cortijo, el señorito Iván. Falta el odio concebido como una tara social" ${ }^{(7)}$.

\section{HUMILDES “NATURALES" Y OPRESORES "PROGRESISTAS”}

\subsection{Sintonía con el entorno y autenticidad}

El ambiente natural tiene gran importancia en muchas novelas y relatos de Delibes. En su primera novela La sombra del ciprés es alargada (1948), la belleza austera de la ciudad de Ávila es un elemento decorativo, tiene sólo valor estético. En El camino (1950), el protagonista, Daniel, está muy integrado en el ambiente de su pueblo montañés y no podemos imaginarlo fuera de allí. En las obras posteriores de Delibes, la naturaleza va tomando otros aspectos más vitales, como lugar donde los hombres conviven o malviven. Así la visión de la naturaleza (especialmente la campestre) deja de ser idílica y se hace más humanizada y, por tanto, más realista y crítica. Desde Las ratas hasta Los santos inocentes, la imagen de los pueblos castellanos o del cortijo extremeño es a veces desoladora. Como en todas sus novelas rurales, también aqui Delibes presenta el campo de las regiones interiores de España de modo muy objetivo, mostrándonos la pobreza económica y penuria cultural, la despoblación, soledad y falta de ilusiones de esa sociedad campesina. Así, en opinión de algunos autores, Delibes ofrece una imagen de Castilla muy distinta a la idealizada y lírica de los escritores de la generación del $98^{(8)}$.

En Los santos inocentes, como en otras novelas de ambiente campestre, Delibes subraya la actitud de la gente humilde, que se siente en sintonía con su entorno natural. Ahí podemos ver una especie de contracultura basada en los saberes de los campesinos integrados en su ambiente, frente a los 
conocimientos y técnicas de los poderosos, que a veces únicamente están "informados". Así la sensibilidad de Azarías hacia las aves y la habilidad de Paco para recoger las piezas, son algo digno de alabanza incluso para los señoritos de Madrid: "Paco se vanagloriaba de que lo que más envidiaran los amigos del señorito Iván, fueran sus facultades y su disposición para la cobra, ni el perro más fino te haría el servicio de este hombre, Iván, que no sabes lo que tienes, le decían" (9). Pero lo que destaca en esta novela posiblemente más que en otras de Delibes, es el hecho de que los campesinos no sólo están en armonía y arraigados en su entorno natural; es que ellos llevan una vida dura, pero tranquila, sin afán de competencia entre sí. Dentro de su pobreza, están más preocupados por ser ellos mismos que por poseer muchas cosas. En definitiva, llevan una vida libre de ostentación, en armonía con la naturaleza, una vida más auténtica que los señores. Precisamente, tener y aparentar más es lo que buscan bastantes señoritos de la ciudad que vienen al cortijo a cazar. Delibes, en la línea de la novela social, no idealiza el campo y crítica duramente las condiciones de vida de los campesinos y la degradación del mundo rural; pero ve ahí una vida humana más digna, a pesar de las miserias y el atraso. Los humildes de esta novela, Régula, Nieves, Quirce, Paco y, sobre todo, el "inocente" Azarias, tienen unas relaciones humanas más profundas y una mayor sintonía con el entorno natural donde viven. Pero también se nota cierto fatalismo y resignación pasiva en bastantes de ellos, cosa que Delibes intenta asimismo subrayar. A veces algún personaje, como el joven Quirce, se rebela contra esa situación: “¿qué puede ocurrirle al Quirce de un tiempo a esta parte? se preguntaba la Régula, pero el Quirce no daba explicaciones y, cada vez que disponía de dos horas libres, desaparecía del Cortijo y regresaba a la noche, un poco embriagado y grave, que nunca sonreía, nunca" ${ }^{(10)}$.

\subsection{Abuso de la naturaleza y progreso}

Delibes en muchos de sus relatos trata el tema de la armonía y amor a la naturaleza. Pero no adopta nunca una visión unilateral de la naturaleza, idílica $o$ artificial. Conoce muy bien el campo y sus problemas para tomar posturas falsamente idealistas. El desarrollo que había comenzado en la sociedad industrial española de los años 60 y la lenta mecanización del campo son 
factores de progreso que apenas aparecen en esta novela. Probablemente porque ese progreso y desarrollo son controlados por grupos que no respetan demasiado la naturaleza, Delibes los ve como algo censurable. Él ha sido acusado de tener una actitud negativa hacia la civilización, de considerar el progreso como cosa opuesta a la naturaleza. Creo que Delibes no está en contra del desarrollo y el progreso en sí mismos, sino de una clase de progreso deshumanizador que produce alejamiento de la naturaleza, materialismo de la vida, y hace a los hombres insolidarios e injustos, como los señores del cortijo en esta novela. Así dice Edgar Pauk que "con el pasar de los siglos y de los milenios el hombre ha 'progresado', es decir, ha construido una civilización que tiene siempre menos contacto con la naturaleza...Lo que Delibes no olvida es que la tecnologia -y gran parte del progreso y civilización es sólo tecnologíaes sólo un instrumento del hombre, pero un instrumento que domina a su amo cada día más" (11).

Así Delibes en Los santos inocentes plantea el problema del desarrollo que está injustamente controlado por los señores. Los criados no pueden acceder nunca a ese progreso porque, ante todo, les falta la instrucción básica. En ese sentido son de admirar los deseos de Paco de promocionar a sus hijos, de enviarlos a la escuela para que pudiesen "salir de pobres con una pizca de conocimientos". Por parte de la señora Marquesa, hay que reconocer que durante tres veranos hizo venir a dos educadores de la ciudad para enseñar a los criados la lectura básica. Incluso el señorito Iván quiso demostrar ante René el francés que los criados y criadas del cortijo sabían escribir sus nombres propios ${ }^{(12)}$. Pero esa alfabetización elemental es insuficiente en una época industrializada y tecnológica. Por eso, según Delibes, el progreso y desarrollo que no tienen en cuenta la capacitación del individuo para adquirirlos y aplicarlos son inoperantes. Sus críticas contra la segregación de clases, la desigualdad que produce el monopolio de la tecnología por los más favorecidos, y el peligro de deshumanización de la gente moderna, las ha expuesto en su novela Parábola del náufrago (alienación del hombre="borrego" en la sociedad capitalista), y de modo diferente en Los santos inocentes. Aquí esa deshumanización se produce por la opresión de los humildes tratados como objetos, usados cuando son rentables y desechados cuando ya no son 
útiles. Aunque no se trate de un progreso técnico, el desarrollo representado por los señores del cortijo es monopolizado, deshumanizador y, en ese sentido, criticable. Como dice María Isabel Butler, "el peligro del progreso consiste para Delibes en la actitud paternalística de los que lo administran. La aplicación de los adelantos materiales se convierte con frecuencia en un predominio de la sociedad de consumo en perjuicio de las clases desposeídas" (13).

Así pues, Delibes no censura el progreso en sí, y de hecho ha abogado por el desarrollo y la culturización de los campesinos en esta novela y muchos de sus escritos. Lo que él critica es una actitud exclusivista y opresora del progreso. Además ve ahí un peligro de destrucción de la naturaleza, al aplicar técnicas que sólo buscan la rentabilidad a corto plazo sin reparar en los daños ecológicos. Como él mismo dice, "el verdadero progresismo no estriba en un desarrollo ilimitado y competitivo, ni en fabricar cada día más cosas, ni en inventar necesidades al hombre, ni en destruir la Naturaleza...sino en racionalizar la utilización de la técnica, facilitar el acceso de toda la comunidad a lo necesario, revitalizar los valores humanos y establecer las relaciones hombre-naturaleza en un plano de concordia" (14).

\section{VENGANZA DE LA NATURALEZA EXPOLIADA}

\subsection{Peligro destructor del medio natural}

En Los santos inocentes hay bastantes casos en que los poderosos destruyen el medio natural deliberadamente. Esto se realiza, sobre todo, a través de las actividades de caza, a las que el señorito Iván era muy aficionado. Su pasión incontrolada por la caza lleva consigo desprecio a la naturaleza. Así vemos cómo ordena a Paco sacar los ojos a los palomos de reclamo; una mañana que no había cazado nada, se puso a disparar a todos los pájaros a diestro y siniestro; después mató la grajilla de Azarias por despecho. Además las cacerías en batida (grupos de ojeadores levantan bandadas de perdices que son matadas fácilmente por los cazadores desde sus puestos), suponen la eliminación de muchos pájaros y una degradación de la naturaleza. Así la caza aparece en esta novela como una actividad que produce la destrucción del medio ambiente. Es paradójica esta presentación de la caza, teniendo en cuenta que Delibes es un gran aficionado a ese deporte y sobre eso ha escrito 
varios libros. Precisamente porque él conoce bien lo que es y lo que no debe ser la caza, la critica bastante en esta novela. Para Delibes la caza es un medio de aumentar el contacto con la naturaleza, un modo de reforzar el afecto entre el hombre y su entorno natural. Además la caza puede ser una terapia para orientar el espíritu competitivo y la agresividad de la gente en una dirección no destructiva. Según Delibes, la caza debe ser un deporte con unas reglas de juego que den iguales oportunidades a los oponentes: hombre y animal. Por eso él critica la "caza aristocrática" en batida que hace el señorito Iván: "Los señores cobran grandes ramos de perdices y se retratan con ellos y lo celebran con whisky. Este tipo de caza es opuesto a la del hombre libre, sobre naturaleza libre, contra pieza libre... en las batidas hay una relación de causa a efecto entre las perdices y una serie de asuntos políticos, económicos, diplomáticos, que nada tienen que ver con ellas" (15).

Aun así, parece extraño que Delibes, tan amante de la naturaleza y de la ecología, sienta a la vez tanta afición por la caza, que supone matar animales indefensos por pasatiempo. Cuando esa afición llega a ser una pasión incontenible, puede causar tragedias graves, como vemos en Los santos inocentes. Porque la naturaleza, tan pacifica a primera vista, cuando es agredida puede revolverse y aniquilar al hombre. Así, cuando el progreso, la tecnología, la industrialización, o el simple deporte destrozan la naturaleza, ésta se venga y puede poner en peligro la vida humana. En esta novela de ambiente rural, espacio reducido y relaciones humanas muy limitadas, el peligro destructor del medio natural expoliado se presenta de modo simbólico y personalizado, contado como una narración lírica. Pero Delibes es muy consciente del gran riesgo que suponen, no una cacería salvaje en un cortijo alejado, sino la destrucción de bosques y montes, desecación de aguas, calentamiento de la atmósfera, manipulación genética, cambio del equilibrio ecológico, engorde artificial de animales comestibles ("vacas locas"), y una larga lista de agresiones a la naturaleza. Como él mismo dice, "el hombre-supertécnico, armado de todas las armas, espoleado por un afán creciente de dominación, irrumpe en la Naturaleza y actúa sobre ella en dos sentidos, a cuál más deplorable y desolador: desvalijándola y envileciéndola. Las consecuencias pueden ser catastróficas" (16). 


\subsection{Azarías, símbolo de los seres indefensos}

Los santos inocentes termina bruscamente con la escena del asesinato del señorito Iván, perpetrado por Azarías. Como sugiere el título mismo de la novela, Azarias, junto con la niña subnormal Charito (la Niña Chica), son "inocentes", es decir, libres de culpa, sin malicia, y a la vez "santos", o sea, sin pecados, en estado puramente "natural". Así lo reconoce Régula, madre de la niña y hermana de Azarías: "pero, bien mirado, el Azarías era un engorro, como otra criatura, a la par que la Niña Chica, ya lo decía la Régula, inocentes, dos inocentes, eso es lo que son" (17). Los otros oprimidos, en cierto sentido también son "inocentes", es decir, son usados y menospreciados sin motivo ni culpa cometida por ellos mismos. Así todos ellos, pero especialmente Azarías, son una parte de la naturaleza que está siendo expoliada sistemáticamente por los señores del cortijo. Por eso, Azarías es el centro real de la novela, aunque no sepa casi hablar ni sea capaz de realizar una actividad planificada. Su retraso mental, su pobreza y miseria, su ignorancia y suciedad, y sus perturbaciones psíquicas, lo hacen inútil para una relación humana normal. Pero tiene una gran ternura hacia sus familiares y siente un enorme afecto visceral por la naturaleza, sobre todo hacia sus "milanas" que criaba con sumo cariño. De ahí que para él era mucho más importante su grajilla que una persona humana perversa, como el señorito Iván. Por eso, cuando éste mató la grajilla, Azarías reaccionó de modo automático, primario, y aquella misma tarde ahogó con una soga al agresor injusto. Así, en el esquema de esta novela, Azarías es un símbolo de la naturaleza, es como un trozo de naturaleza en estado puro. Cuando esa naturaleza es agredida y expoliada por el hombre, en aras del progreso o por diversión, puede a veces rebelarse y liquidar al agresor. Ésta es la razón de por qué Delibes ha hecho que fuera el "inocente" Azarías precisamente quien se encargase de ejecutar la venganza contra el opresor Iván. Como dice Javier Sánchez, “Azarías es un ser en la naturaleza. Es el símbolo fuera de la Historia y de la Civilización, reducido sólo a naturaleza, a instinto. A su través Delibes sigue presentando su antinomia Naturaleza-Progreso... Azarías está al margen del devenir de la historia, de la marcha del progreso, de los avances de la civilización. Es pura naturaleza. Por eso es inocente" (18). 
El lugar y el modo de la ejecución del crimen también tienen un sentido simbólico. Subido a una encina, Azarías llama la atención de Iván. Cuando éste levanta la cabeza, Azarías le echa al cuello la soga con el nudo corredizo. Iván, ahorcado, queda colgando del árbol, mientras Azarias exclama: "milana bonita, milana bonita" (19). El árbol es un elemento natural que simboliza al hombre, pero puede tener también un valor transcendente y hierofánico (manifestación de lo sagrado), como vemos en muchas culturas. En España el ciprés es el árbol de los cementerios y su connotación de "muerte" es innegable. Delibes, desde su primera novela La sombra del ciprés es alargada, ha subrayado la influencia de los árboles en la vida del hombre. Así Iván, vengado por un hombre en estado "natural", termina colgado de un árbol. Por otra parte, el hecho de que sea Azarías quien ejecuta la venganza de los "inocentes" contra el explotador Iván, quita a esa rebelión su posible sentido político y social. Como dice Domingo Gutiérrez, "no se trata de una rebelión 'política', sino de una venganza individual. Un retrasado mental comete un crimen por algo que a él le han hecho y que le afecta a él solo... Pero al lector este crimen se le aparece como un acto de 'justicia natural' que posee dos características: estar exento de culpabilidad -porque lo comete un retrasado mental-, y constituir un resarcimiento de todos los humildes por las injusticias y oprobios sufridos" (20).

Hay en la novela muchos motivos y personas que podrian haberse rebelado violentamente contra los señores opresores. La injusticia social y la opresión son un tema muy importante de este relato. Pero el final de la obra define y refuerza la línea ecologista de esta narración y concretiza su mensaje. La naturaleza expoliada, es decir, un ser que es parte casi irracional e inculpable de esa naturaleza, se alza contra la agresión injusta de un señorito que ha matado por enfado un pájaro inofensivo. ¿Es eso razón suficiente para asesinar a una persona? En la lógica de un hombre normal tal vez no lo sea, pero visto desde el sentimiento visceral de un subnormal sí fue motivo real, justificado o no. Es una venganza "natural", simbólica, ejecutada por un "inocente" que representa a la naturaleza y sus seres más indefensos.

\section{CONCLUSIÓN}

Los santos inocentes es una novela muy importante de los años 80 en 
España y una de las obras clave en la narrativa de Delibes. Como novela "experimental", sus innovaciones, no sólo tipográficas, son valiosas. Además su estilo coloquial y su lenguaje "oral" son muy característicos. Es quizá la única novela española escrita en estilo hablado, con giros, expresiones, palabras, exclamaciones, epítetos y locuciones verbales tan bien imitados de la lengua diaria rural. Así se puede decir que su estilo y léxico son su mayor originalidad. Pero también los tipos humanos que aparecen en la novela, sobre todo Azarías, Iván y Paco son personajes bien caracterizados y cuentan sus actividades e interioridad con mucha sinceridad. Delibes muestra aquí de nuevo su gran preocupación por la degradación del ser humano y de su entorno natural. También vemos una fuerte denuncia de las injusticias sociales y opresión de los débiles, de la incultura y falta de instrucción, de la penuria económica y de la inutilidad de los latifundios. Pero Delibes critica todas esas cosas sin plantear una "tesis" preconcebida que desee demostrar. Él simplemente observa como testigo y expone los hechos a nuestra consideración; mejor dicho, los lectores captamos ese mensaje crítico al ver lo que sufren los personajes, cómo viven y qué dicen. También hay una condena contundente del sistema destructor de la naturaleza en el asesinato final.

Las condiciones de vida en la agricultura latifundista española de los años 60 eran intolerables y se necesitaba no sólo una denuncia pública, sino también una reforma estructural. Delibes suscitó el problema, pero no fue una intención política lo que motivó esta novela, como él mismo dice: "La situación de sumisión e injusticia que el libro plantea, propia de los años 60, y la subsiguiente 'rebelión del inocente' han inducido a algunos a atribuir a la novela una motivación política, cosa que no es cierta. No hay política en este libro. Sucede, simplemente, que este problema de vasallaje y entrega resignada de los humildes subleva tanto a una conciencia cristiana como a un militante marxista. Afortunadamente estas reminiscencias feudales van poco a poco quedando atrás en nuestra historia" (21). Es precisamente esa falta de compromiso político una deficiencia de las novelas de Delibes que algunos críticos han señalado. Pienso que el énfasis más ecológico y naturalista de Los santos inocentes ha marcado su enfoque y desarrollo. Pero es cierto que Delibes ha sido indeciso en sus planteamientos socio-políticos, aun 
reconociendo el freno de la censura franquista de aquella época.

Otra cosa que sorprende en esta novela es la imagen negativa de la caza (aunque sea la "aristocrática"), cuando al autor le gusta tanto esa actividad. Realmente es difícil compaginar ecologismo y caza, y parece que ésta no cuadra bien con los principios morales y estéticos de Delibes. Es una visión del arte cinegética algo contradictoria pero explicable, porque el mensaje final de la novela es el amor a la naturaleza y el peligro de venganza de ésta cuando es agredida insolentemente por el hombre.

\section{NOTAS}

(Para la referencia completa de las obras citadas, véase la BIBLIOGRAFÍA).

(1) Javier Goñi, op.cit., p.60. Cf. también Francisco Umbral, op.cit., pp.111-113.

(2) Domingo Gutiérrez, op.cit., p.72. Cf. también pp.68-70, 62-64.

(3) Cf.Miguel Delibes, Los santos inocentes, Planeta, Barcelona, 1996, pp.52, 93, 143.

(4) Cf.Manuel Alvar, op.cit., pp.61-71. Dice que es un realismo local, detallista, auténtico, no convencional, poético y revelador de la intimidad personal.

(5) Los santos inocentes, p.27. Cf. también pp.85, 113, 165.

(6) Los santos inocentes, p.144. Cf. también pp.45-47, 66-68, 137-140.

(7) Pedro Carrero, op.cit., p.4. Delibes ha estudiado también la intolerancia religiosa (Inquisición de Valladolid) en la sociedad castellana del siglo XVI, en su excelente novela histórica El hereje, Destino, Barcelona, 1998.

(8) Cf. Francisco Umbral, op.cit., p.87 (dice que Delibes "ha desnoventayochizado" Castilla).

Cf. también Pilar Puente, op.cit., pp.106-109 (compara a Delibes con escritores del 98).

(9) Los santos inocentes, p.97. Cf. también pp.19-21, 81-84.

(10) Los santos inocentes, pp.70-71. Cf. también Ramón Garcia, op.cit., pp.65-69.

(11) Edgar Pauk, op.cit., pp.159, 161. Cf. también pp.165-168.

(12) Cf. Los santos inocentes, pp.34-37, 42, 104-106. Cf. M. Alvar, op.cit., pp.112-114.

(13) Maria Isabel Butler, op.cit., p.590. Cf. también pp.586-588.

(14) M.Delibes, S.O.S. El sentido del progreso en mi obra, Destino, Barcelona, 1976, pp.20-21.

(15) César Alonso, op.cit., p.211. Para ver sus ideas sobre el valor positivo de la caza, cf. Delibes, El libro de la caza menor, Destino, Barcelona, 1965, pp.16, 105, $194-197$.

(16) M.Delibes, Un mundo que agoniza, Plaza\&Janés, Barcelona, 1998, pp.86-87.

(17) Los santos inocentes, p.68. Cf. también pp.71-72, 110.

(18) Javier Sánchez, op.cit., p.97 (en otras novelas de Delibes, los “inocentes" son niños).

(19) Cf. Los santos inocentes, pp.175-176. Cf. también M.I.Butler, op.cit., p.593. 
(20) D.Gutiérrez, op.cit., p.77. P.Carrero en op.cit., pp.4-5, compara a Azarías con los criminales-inocentes de La familia de Pascual Duarte y otras novelas.

(21) Carta enviada por Miguel Delibes para la edición de Los santos inocentes, Círculo de Lectores, Barcelona, 1985; citada por D.Gutiérrez, op.cit., p.72.

\section{BIBLIOGRAFIA}

ALONSO, C.(1971): Conversaciones con Miguel Delibes, Madrid, Magisterio Español.

ALVAR, M.(1987): El mundo novelesco de Miguel Delibes, Madrid, Gredos.

BUTLER, M.I.(1975): Relación Hombre-Naturaleza en E.M. Forster y Miguel Delibes,

Cuadernos Hispanoamericanos, 300, pp.572-597.

CARRERO, P.(1982): El "leitmotiv" del odio y de la agresión en las últimas novelas de Delibes, Ínsula, 425, pp.4-11.

GARCÍA, R.(1985): Miguel Delibes: un hombre, un paisaje, una pasión, Barcelona, Destino.

GON̄I, J.(1985): Cinco horas con Miguel Delibes, Madrid, Anjana.

GUTIÉRREZ, D.(1989): Claves de Los Santos Inocentes, Madrid, Ciclo.

PAUK, E.(1975): Miguel Delibes: desarrollo de un escritor(1947-1974), Madrid, Gredos.

PUENTE, P.(1986): Castilla en Miguel Delibes, Salamanca, Ediciones Universidad.

SÁNCHEZ, J.(1985): El hombre amenazado. Hombre, sociedad y educación en la novelística de Miguel Delibes, Salamanca, Universidad Pontificia.

UMBRAL, F.(1970): Miguel Delibes, Madrid, Epesa. 
$\langle$ Resumen〉

\section{“LOS SANTOS INOCENTES”: NATURALEZA Y PROGRESO INSOLIDARIO}

\section{Ceferino PUEBLA PEDROSA}

Los santos inocentes (1981), de Miguel Delibes, es una novela con innovaciones técnicas, tipográficas y estilisticas muy importantes. Consta de 6 Libros que tienen cada uno su título y cierta autonomia, como si fuesen relatos casi independientes. Pero la novela tiene una fuerte cohesión argumental que proviene de sus coordenadas espacio-temporales y de su tema central: la opresión de los pobres campesinos en un latifundio extremeño en los años 60 por parte de los señores del cortijo. Éstos humillan a la gente y abusan de la naturaleza, sobre todo con sus crueles actividades de caza. Por eso, el "inocente" Azarias al final venga a la naturaleza ultrajada asesinando al amo de la hacienda. Con un estilo coloquial, con un bello lenguaje "oral" y léxico rural, Delibes avisa sobre el peligro de un progreso contranatural, que es insolidario con los desposeidos y destructor del medio ambiente. Novela clave en la narrativa española de finales del sigo XX y obra maestra de su autor, este relato muestra un profundo humanismo y una preocupación ecologista muy actual. 